\title{
Northern vision of a research centre for Europe
}

London

Against the continuing gloom over the state of British research, the launch last week of an appeal to establish a European eye and brain research institute at Manchester provided a gleam of optimism. The sponsors hope to raise $£ 15$ million in the next ten years, from industry, commerce and private donors, to provide a self-financing centre for basic and clinical research in the vision sciences.

Professor John Cronly-Dillon, of the department of ophthalmic optics at the University of Manchester Institute of Science and Technology (UMIST), offers as a model for the new centre international laboratories such as the European Molecular Biology Laboratory at Heidelberg. At a meeting of potential backers last week, he declared his ambition that the new centre, to be known as the Northern Eye Institute (NEI), will provide a focus for research into both basic and clinical sciences related to vision and brain function and that it should attract workers from all over the world.

Basic research will range from molecular approaches to genetic and virusrelated neurological diseases to machine intelligence. Clinics will be established for research into and treatment of visual complications of diseases such as diabetes and multiple sclerosis, as well as littleunderstood problems of visual recognition such as dyslexia. There will be space for industrial researchers to develop commercial applications of instruments and treatments initiated at the institute.

The plan is that the centre should grow in stages, each financed by the interest on the accumulating endowment, with a start on the construction of a building in about five years. Meanwhile, the interest on the invested capital would be used to support vision research in Manchester, with the NEI acting as an umbrella for existing vision research groups at the Manchester University Medical School, UMIST and the Manchester Eye Hospital.

Eventually, according to the plan, the centre should be self-financing on the basis of income from interest, clinic fees, bench fees from visiting workers and overheads on research grants to members of the permanent staff, of which there will be a nucleus on five-year contracts. There will also be income from the expansion of the existing NEI programme of conferences, seminars and teaching courses.

Part of the objective is to find an alternative means of financing research, but there are some fears that initiatives like this could damage the structure of basic research in Britain by absorbing the best

\section{Japan's Ginga (ASTRO-C) X-ray satellite}

Tokyo

THE picture shows the launch of Japan's Ginga (ASTRO-C) X-ray satellite at $\mathbf{1 5 0 0}$ Japan Standard Time from the Kagoshima Space Center on 5 February (see Nature $325,567 ; 1987)$. The photograph was taken by scientists of the Institute of Space and

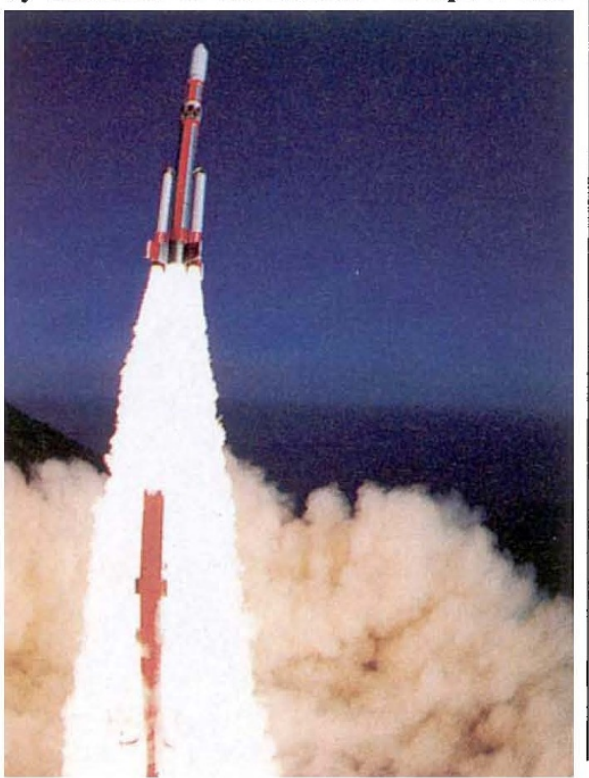

Astronautical Science (ISAS) with a remote-controlled camera mounted at the top of the assembly tower. Dr Makishima of Tokyo University, who provided the photograph, would like to emphasize that the M-SII-3 rocket is not bent - that is an effect of the fish-eye lens.

The rocket was launched at an angle, rather than vertically, to save power. As the little 28 -m solid-fuel rocket streaked heavenward, it was buffeted by strong cross-winds and precious power was used up in course corrections.

As a result, the satellite did not quite make its planned circular orbit of $600 \mathrm{~km}$ but entered an elliptical orbit of between 505 and $675 \mathrm{~km}$, a situation which creates a variable X-ray background for the satellite's detectors. But this is not an insurmountable problem according to Makishima.

Within days of the launch, ISAS scientists had something spectacular to test the satellites large-area proportional counters on - the supernova in the Large Magellanic Cloud. But, unfortunately, an X-ray source (LMC X-1) only 0.6 degrees away is obscuring their observations.

David Swinbanks people and by allowing complacency among funding organizations. Those from universities presenting demontrations of their work at last week's meeting said that vision research in Britain is already falling behind that in Europe and North America. Colin Blakemore, professor of physiology at the University of Oxford (who is in California this week considering two job offers) said that centres such as the planned eye institute should be seen as the pinnacle of a pyramid, not the pyramid itself.

Jennifer Altman

\section{AIDS institute for India? \\ New Delhi}

THE Indian Council of Medical Research (ICMR) is advocating a National Institute for AIDS (acquired immune deficiency syndrome) for research and to treat patients. By 1 March 1987, 104 cases of infection had been detected in India out of 30,000 people so far screened at ICMR's referral centres. At least four new cases are detected every two weeks.

Because many of the infected cases are expected to develop the disease, a hospital exclusively for AIDS is now considered necessary; existing hospitals are overcrowded and are not equipped to deal with AIDS patients.

Indian health officials say that AIDS reached India chiefly through tourists and foreign students. Of the 104 cases so far identified, 11 were foreign students, 11 were tourists and 76 were female prostitutes; only five were Indian males.

Many of the prostitutes in Tamil Nadu claim to have had sexual relations with foreign priests attending Christian conventions. With the discovery of AIDS among Roman Catholic priests, their role in transmitting AIDS is not ruled out, say Indian officials.

Priority for screening has been given to prostitutes because of the large pool of infection among them. But since the Calcutta police gaoled a prostitute suspected of having AIDS, prostitutes all over India have refused to give blood for AIDS tests, which are not at present compulsory because prostitution is illegal. There is a proposal to legalize prostitution and to make the AIDS test mandatory as a condition of granting a licence.

For administrative reasons, the Indian government has dropped the idea of screening tourists, but it has refused to reverse its decision to screen foreign students. Eleven African students have so far been deported. Last week, a Swiss national gaoled for possession of heroin was deported after he said he had AIDS; his accomplice, also a Swiss, has now demanded to be deported by claiming that he shared a bed with his friend in the city gaol.

K.S.Jayaraman 